\title{
Femoral vein obturator bypass revascularization in groin infectious bleeding: two case reports and review of the literature
}

\author{
Albert Busch*, Udo Lorenz, George Christian Tiurbe, Christoph Bühler and Richard Kellersmann
}

\begin{abstract}
Introduction: Groin infections resulting in arterial bleeding due to bacterial vessel destruction are a severe challenge in vascular surgery. Patients with them most often present as emergencies and therefore need individualized reconstruction solutions.
\end{abstract}

Case presentation: Case 1 is a 67-year-old man with infectious bleeding after an autologous reconstruction of the femoral bifurcation with greater saphenous vein due to infection of a bovine pericard patch after thrombendarterectomy. Case 2 is a 35-year-old male drug addict and had severe femoral bleeding and infection after repeated intravenous and intra-arterial substance abuse. Both patients were treated with an autologous obturator bypass of the superficial femoral vein. We review the current literature and highlight our therapeutic concept of this clinical entity.

Conclusions: Treatment should include systemic antibiotic medication, surgical control of the infectious site, revascularization and soft tissue repair. An extra-anatomical obturator bypass with autologous superficial femoral vein should be considered as the safest revascularization procedure in infections caused by highly pathogenic bacteria.

Keywords: Obturator bypass, Groin infection, Autologous, Extra-anatomical, Femoral vein

\section{Introduction}

Severe groin infections with inguinal blood vessel destruction may be caused by intravenous substance abuse, radiation scars, transfemoral interventions and, most commonly, infection of prosthetic vascular implants (incidence $2 \%$ to $18 \%$ ) [1-4]. Complications include life-threatening bleeding, acute ischemia, septic embolization and systemic sepsis. Finding the appropriate strategy for each patient remains an individual challenge.

\section{Case presentation}

Case 1

A 67-year-old Caucasian man was admitted to our institution with infectious bleeding in the right groin and lower limb ischemia 4 months after a prolonged hospitalization

\footnotetext{
*Correspondence: busch_a2@chirurgie.uni-wuerzburg.de

Department of General, Visceral, Vascular and Paediatric Surgery University Clinic of Würzburg, Oberdürrbacher Strasse 6, Würzburg D-97080, Germany
}

for common femoral artery thrombendarterectomy with a bovine pericard patch plasty and successful antibiotic treatment due to postoperative methicillin-resistant Staphylococcus aureus (MRSA) superinfection of an inguinal lymphatic fistula. For surgical control of bleeding, orthotopic revascularization with iliacofemoral and iliacoprofundal greater saphenous vein interposition and resection of the xenogenic patch material was performed, accompanied by systemic MRSA-specific antibiotic treatment. Three weeks later rebleeding occurred due to an infectious arterial pseudoaneurysm. Intra-operative findings revealed complete erosion of the profundal venous graft anastomosis (Figure 1A).

\section{Case 2}

A 35-year-old Caucasian man with extensive groin infection due to repeated drug abuse via the femoral vessels was transferred to our hospital 1 day after emergency implantation of an iliacofemoral and iliacoprofundal polytetrafluoroethylene prosthesis due to infectious bleeding 

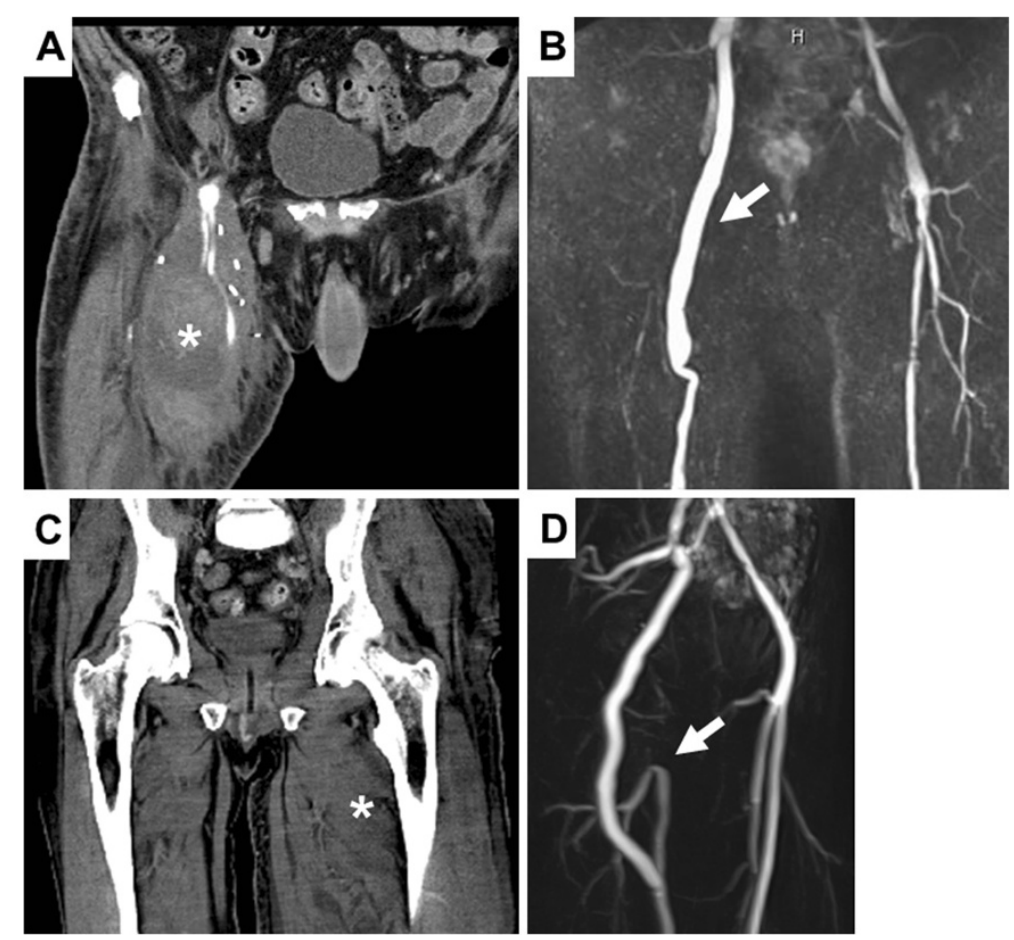

Figure 1 (A) Computed tomography scan of case 1 obtained after rebleeding due to septic pseudoaneurysm showing liquid, putrid formation (asterisk) with arterial extravasation caused by erosion of the distal anastomosis of the greater saphenous vein interposition and extensive perifocal soft-tissue edema in the right upper thigh. (B) Magnetic resonance angiogram of the obturator bypass in case 1 nearly 3 years after bypass surgery showing bypass perfusion free of stenosis (arrow). Case 2 (C) Computed tomography scan of case 2 at time of admission showing swelling, subcutaneous purulent formation and perifocal edema (asterisk). (D) Magnetic resonance angiogram obtained 3 months after surgery in case 2 showing the obturator bypass with retrograde perfusion of the profundal femoral artery by additional end-to-end anastomosis with proximal superficial femoral artery (arrow).

together with rhabdomyolysis and sepsis with liver and kidney failure (Figure 1C). Massive gangrenous destruction of the femoral vessels and surrounding tissue were found intra-operatively, pending sufficient coverage of an orthotopic revascularization (Figure 2A). Group B Streptococcus was identified.

An obturator bypass using the ipsilateral superficial femoral vein to bypass the infected area extra-anatomically from the common iliac artery to the distal femoral artery was performed in both cases (Figures 2A and 2B). Venous graft was harvested from the non-infectious part of the thigh to the venous confluence. This procedure was accompanied by systemic antibiotic therapy, then by local debridements and finally by mesh graft augmentation. Physical therapy and $30 \mathrm{mg}$ enoxaparin daily were administered from day 1 after the operation. The patients were dismissed in good health and able to walk with regression of initial lymphatic swelling. Both bypasses remained patent during follow-up at 32 and 12 months in cases 1 and 2, respectively (Figures $1 \mathrm{~B}$ and $1 \mathrm{D}$ ).
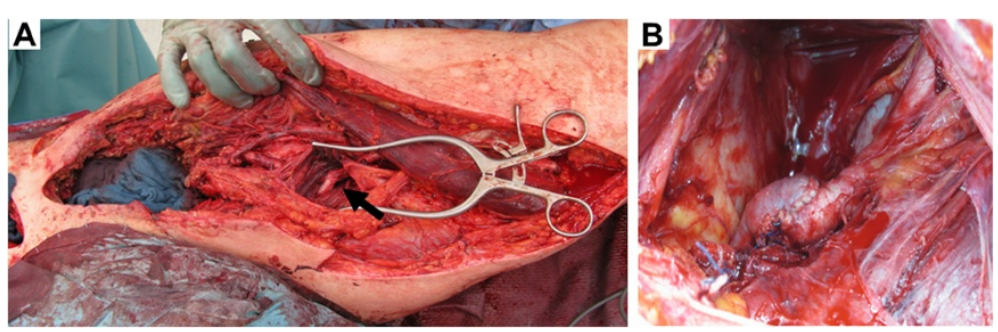

Figure 2 Intra-operative images. (A) The intraoperative site after radical debridement and the distal anastomosis of the implanted bypass (arrow) with gross incisions opening the whole upper thigh. (B) Suprapubic incision showing the proximal anastomosis before leaving the pelvic region through the obturator foramen. 
Venous function was not hindered clinically, with normal thigh circumference.

\section{Discussion}

Though challenging, individual primary revascularization procedures, especially in young patients, should be considered the first treatment option because of high amputation rates after double or triple ligation (up to 27\%) or severe claudication [4-7]. Without complete graft removal, reinfection occurs in about one-third of cases [8]. Insufficient soft-tissue coverage at the infection site weighs in favor of an extra-anatomic bypass configuration.

The obturator bypass, with primary patency rates of up to $76 \%$ after 2 years, has proven to be feasible in a few small clinical series with a considerable risk of late prosthetic graft infection remaining [1,3,4,9-11]. Therefore, evidence is increasing for the superiority of autologous revascularization with femoral veins to allograft, xenograft or synthetic materials, as well as greater saphenous vein (complete erosion despite antibiotic therapy in case 1) in terms of infection resistance, patency rates and availability [12-15].

To the best of our best knowledge, investigators of only one clinical series have reported the use of obturator bypass fashioned from autologous superficial femoral vein at infection sites [16]. We therefore want to highlight in our case presentations its potential benefits in vascular groin infections, with a crucial focus on the underlying bacteriology, such as MRSA and Group B Streptococcus in this report. With proven susceptibility of several native and prosthetic materials to MRSA and rising clinical incidence, femoral vein obturator bypass is the safest revascularization procedure with the best long-term results [17].

\section{Conclusions}

The extra-anatomic obturator bypass with femoral vein is a safe and feasible revascularization procedure in patients with severe groin infections and highly pathogenic bacteria such as MRSA, Pseudomonas aeruginosa and Group B Streptococcus. It should be considered the primary treatment option by vascular surgeons confronted with this problem, especially in young patients.

\section{Consent}

Written informed consent was obtained from the patients for publication of this case report and any accompanying images. A copy of the written consent is available for review by the Editor-in-Chief of this journal.

\section{Competing interests}

The authors declare that they have no competing interests and did not receive any payment from industrial partners.

\section{Authors' contributions}

$\mathrm{RK}, \mathrm{CB}, \mathrm{CT}$ and $\mathrm{AB}$ performed surgery on the patients and were responsible for postoperative intensive medicine care. UL performed vascular graft infection studies in mice and was a major contributor in writing the manuscript. All authors read and approved the final manuscript.

\section{Acknowledgements}

This publication was funded by the German Research Foundation (DFG) and the University of Wuerzburg in the funding programme Open Access Publishing

Received: 27 June 2012 Accepted: 24 January 2013

Published: 18 March 2013

\section{References}

1. Matoussevitch V, Aleksic M, Gawenda M, Brunkwall J: Primary extraanatomical revascularization for groin infections in drug addicts. Vasa 2007, 36:210-214.

2. Zetrenne E, McIntosh BC, McRae MH, Gusberg R, Evans GR, Narayan D: Prosthetic vascular graft infection: a multi-center review of surgical management. Yale J Biol Med 2007, 80:113-121.

3. Meyer $\mathrm{T}$, Schweiger $H$, Lang W: Extraanatomic bypass in the treatment of prosthetic vascular graft infection manifesting in the groin. Vasa 1999, 28:283-288

4. Engin C, Posacioglu $H$, Ayik F, Apaydin AZ: Management of vascular infection in the groin. Tex Heart Inst J 2005, 32:529-534.

5. Scheuerlein $H$, Ruff $S$, Haage $P$, Zirngibl H, Fraunhofer $S$, Settmacher U: Groin abscesses and vascular catastrophes in intravenous drug users: strategy and results [in German]. Zentralb/ Chir 2008, 133:55-60.

6. Naqi SA, Khan HM, Akhtar S, Shah TA: Femoral pseudoaneurysm in drug addicts: excision without revascularization is a viable option. Eur J Vasc Endovasc Surg 2006, 31:585-587.

7. Georgiadis GS, Lazarides MK, Polychronidis A, Simopoulos C: Surgical treatment of femoral artery infected false aneurysms in drug abusers. ANZ J Surg 2005, 75:1005-1010.

8. Mayer D, Hasse B, Koelliker J, Enzler M, Veith FJ, Rancic Z, Lachat M: Longterm results of vascular graft and artery preserving treatment with negative pressure wound therapy in Szilagyi grade III infections justify a paradigm shift. Ann Surg 2011, 254:754-759.

9. Ferreira U, Reis LO, Ikari LY, da Silva W Jr, Matheus WE, Denardi F, Stopiglia RM, Menezes FH: Extraanatomical transobturator bypass graft for femoral artery involvement by metastatic carcinoma of the penis: report of five patients. World J Urol 2008, 26:487-491.

10. Patel A, Taylor SM, Langan EM 3rd, Snyder BA, Cull DL, Sullivan TM, Youkey JR, Gray BH, Carsten CG: Obturator bypass: a classic approach for the treatment of contemporary groin infection. Am Surg 2002, 68:653-658.

11. Sautner T, Niederle B, Herbst F, Kretschmer G, Polterauer P, Rendl KH, Prenner K: The value of obturator canal bypass: a review. Arch Surg 1994, 129:718-722.

12. Nevelsteen A, Lacroix H, Suy R: Autogenous reconstruction with the lower extremity deep veins: an alternative treatment of prosthetic infection after reconstructive surgery for aortoiliac disease. J Vasc Surg 1995, 22:129-134.

13. Schulman ML, Badhey MR, Yatco R, Pillari G: A saphenous alternative: preferential use of superficial femoral and popliteal veins as femoropopliteal bypass grafts. Am J Surg 1986, 152:231-237.

14. Biró G, Szeberin Z, Nemes A, Acsády G: Cryopreserved homograft and autologous deep vein replacement for infrarenal aorto and iliacofemoral graft infection: early and late results. J Cardiovasc Surg (Torino) 2011, 52:169-176.

15. Lorenz U, Schafer T, Ohlsen K, Tiurbe GC, Buhler C, Germer CT, Kellersmann R: In vivo detection of Staphylococcus aureus in biofilm on vascular prostheses using non-invasive biophotonic imaging. Eur J Vasc Endovasc Surg 2011, 41:68-75.

16. Benjamin ME, Cohn EJ Jr, Purtill WA, Hanna DJ, Lilly MP, Flinn WR: Arterial reconstruction with deep leg veins for the treatment of mycotic aneurysms. J Vasc Surg 1999, 30:1004-1015.

17. Murphy GJ, Pararajasingam R, Nasim A, Dennis MJ, Sayers RD: Methicillinresistant Staphylococcus aureus infection in vascular surgical patients. Ann R Coll Surg Engl 2001, 83:158-163.

doi:10.1186/1752-1947-7-75

Cite this article as: Busch et al:: Femoral vein obturator bypass revascularization in groin infectious bleeding: two case reports and review of the literature. Journal of Medical Case Reports 2013 7:75. 